\title{
Increased morbidity and mortality in patients with antiphospholipid syndrome undergoing valve replacement surgery
}

\author{
Yackov Berkun, MD \\ Amir Elami, $\mathrm{MD}^{\mathrm{b}}$ \\ Karen Meir, MD ${ }^{\mathrm{c}}$ \\ Dror Mevorach, MD \\ Yaakov Naparstek, MD
}

From the Department of Pediatrics, ${ }^{\text {a }}$ Bikur
Cholim Hospital, and the Departments of
Cardiothoracic Surgery, ${ }^{\text {b Pathology, }}{ }^{\text {c }}$ and
Medicine, ${ }^{\text {d }}$ Hadassah University Hospital,
Jerusalem, Israel.

This work was supported in part by the Adolfo and Evelin Endowment Fund for Rheumatology Research. Y.N. is the incumbent of the Leiferman Chair of Osteoporosis and Arthritis.

Received for publication Feb 16, 2003; revisions requested April 2, 2003; revisions received July 3, 2003; accepted for publication July 14, 2003.

Address for reprints: Amir Elami, MD, Cardiothoracic Surgery, PO Box 12000, Jerusalem 91120, Israel (E-mail: eamir@ md2.huji.ac.il).

J Thorac Cardiovasc Surg 2004;127:414-20

$0022-5223 / \$ 30.00$

Copyright (C) 2004 by The American Association for Thoracic Surgery

doi:10.1016/j.jtcvs.2003.07.016
Objective: Heart valve abnormalities are commonly found in patients with antiphospholipid syndrome but experience with valve replacement in such patients is limited. We analyzed the results of valve replacement in patients with this condition at our institution.

Methods: Between 1989 and 2002, 10 patients with antiphospholipid syndrome (8 women, 2 men; aged 38-73 years, mean 49 years) with severe mitral valve disease $(n=7)$, aortic valve disease $(n=2)$, or combined mitral-aortic disease $(n=1)$ underwent valve replacement. We reviewed retrospectively their clinical data, operative and postoperative courses, and the long-term results. Pathological reassessment was performed in all cases.

Results: Procedures performed included mitral valve replacement in 7 patients, aortic valve replacement in 2 patients, and combined aortic valve replacement plus mitral valve replacement in 1 patient. In addition, 2 patients underwent tricuspid annuloplasty. The immediate mortality was $20 \%$ (2 patients). Major complications occurred in 2 other cases. During a follow-up period of up to 8 years, 2 patients required repeat operation for valve-related complications (1 death). An additional patient died of cardiac causes 13 months after surgery. One patient had major thromboembolic events 3 and 10 months after the operation. The late outcome was uneventful in only 4 patients.

Conclusion: Valve replacement in patients with antiphospholipid syndrome may carry significant early and late mortality and morbidity, particularly when such patients are referred with advanced valvular heart disease.

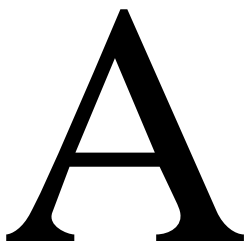

ntiphospholipid syndrome (APLS) is a multisystem autoimmune disease characterized by arterial and venous thrombosis, recurrent fetal loss, thrombocytopenia, and circulating antiphospholipid antibodies. Virtually any organ can be involved: heart (valvular and coronary disease, intracardiac thrombi), central nervous system (CNS)/brain (cerebrovascular accident, transient ischemic attack, seizures, chorea, migraine, pseudotumor cerebri, visual disturbances, dementia), skin (livedo reticularis, ulcers, infarcts, superficial thrombophlebitis), kidney (renal artery or vein thrombosis, acute and chronic renal failure), and bone (hemolytic anemia). ${ }^{1,2}$ This syndrome with protean clinical manifestations can be either primary or secondary to other autoimmune disease, mainly systemic lupus erythematosus (SLE). ${ }^{1,2}$ Although heart valve abnormalities are found in a majority of patients with APLS, ${ }^{3}$ the prognosis of the valvular disease in this condition is not well documented except for the high incidence of thromboembolic events. ${ }^{4}$ Signif- 
icant damage necessitating valve replacement is considered rare, ${ }^{5}$ and data regarding the outcome of valve replacement in patients with APLS are limited and generally restricted to case reports. ${ }^{6-19}$ To examine our own experience with these procedures, we reviewed all patients with APLS (primary and secondary) who underwent valve replacement at our institution during the last 13 years.

\section{Patients and Methods}

Of 2418 patients who underwent valve replacement during the last 13 years at our hospital, 24 patients with either APLS or the presence of anticardiolipin (ACL) antibodies were identified. Of these 24 patients, 14 had a transient elevation of ACL antibodies with no evidence of APLS. Only the remaining 10 patients fulfilled preliminary classification criteria for definite APLS. ${ }^{20}$ These 10 patients form the basis of this report.

The preoperative cardiac findings are summarized in Table 1. There were 8 women and 2 men, who ranged in age from 38 to 73 (mean 49) years. Seven patients had severe mitral valve disease; 1 had combined mitral-aortic valve disease; in 2 male patients the aortic valve was damaged. Preoperatively, 5 patients were classified as New York Heart Association (NYHA) functional class IV, 4 were considered class III, and the remaining patient was in class II. Severe pulmonary hypertension was found in 6 patients. The main clinical and laboratory characteristics of the underlying APLS are shown in Table 2. The syndrome was primary in 5 cases and secondary to SLE in the remaining 5. The mean interval between the first manifestation of APLS and the first (index) operation was 9.7 years (1-22 years). Eight patients had arterial or venous vascular thrombosis in the past. All but 1 patient had CNS involvement and in all but 1 case thrombocytopenia was found. Five patients had mild to moderate renal failure (serum creatinine $130-220 \mathrm{mEq} / \mathrm{dL}$ ). Seven patients were taking prednisone at the time of operation.

\section{Operative Data}

Operative data and outcomes are depicted in Table 3. All operations were performed using standard cardiopulmonary bypass, with full heparinization (activated clotting time $>480$ seconds) and cardioplegic arrest. Operative procedures included mitral valve replacement (MVR) in 7 patients, aortic valve replacement (AVR) in 2 patients, and combined MVR and AVR in 1 patient. Tricuspid annuloplasty was performed in 2 patients concomitantly with MVR. Eight patients received mechanical valves, and 2 patients (patients 3 and 8) received tissue valves. Median sternotomy was performed in 9 cases, whereas right thoracotomy was employed in 1 patient.

Oral anticoagulation with warfarin sodium (Coumadin) was instituted 24 hours postoperatively, and heparin was continued until the international normalized ratio (INR) achieved a target value of 3 to 4 . None of the patients ( 8 of them with preoperative thrombocytopenia) received antiplatelet therapy during the early postoperative period.

\section{Definitions}

Early outcomes included events and complications occurring within the first 30 days after operation or during hospital stay.
TABLE 1. Clinical cardiac findings

\begin{tabular}{rcccc}
\hline Case & $\begin{array}{c}\text { Age/ } \\
\text { gender }\end{array}$ & Valve lesion & $\begin{array}{c}\text { CHF class } \\
\text { (NYHA) }\end{array}$ & $\begin{array}{c}\text { Pulmonary } \\
\text { hypertension* }\end{array}$ \\
\hline 1 & $48 / \mathrm{F}$ & MS,TR & IV & Severe \\
2 & $48 / \mathrm{F}$ & MR & III & Moderate \\
3 & $73 / \mathrm{F}$ & MR & III & Severe \\
4 & $43 / \mathrm{F}$ & MS + MR; TR & IV & Severe \\
5 & $47 / \mathrm{F}$ & AR + AS; MR & IV & Moderate \\
6 & $38 / F$ & MR & III & Severe \\
7 & $51 / F$ & MR,AR,TR & IV & Severe \\
8 & $42 / \mathrm{M}$ & AR, vegetation & IV & Moderate \\
9 & $55 / \mathrm{M}$ & AR + AS & II & Mild \\
10 & $54 / F$ & MS + MR & III & Severe \\
\hline
\end{tabular}

$A R$, Aortic regurgitation; $A S$, aortic regurgitation; $C H F$, congestive heart failure; $M R$, mitral regurgitation; $M S$, mitral stenosis; $T R$, tricuspid regurgitation.

*Systolic pressure by echocardiography or direct measurement (mild $30-45$, moderate $45-60$, severe $>60 \mathrm{~mm} \mathrm{Hg}$ ).

Complications were defined according to guidelines for reporting morbidity and mortality after cardiac valvular operations ${ }^{21}$.

\section{Follow-up}

Patients were followed in our outpatient clinic. Recent clinical evaluation was performed on all surviving patients. The follow-up period was 6 to 96 months (mean 35 months) with a total of 281 patient-months.

\section{Results}

\section{Pathology}

For those entering the study, the pathological evaluation was reassessed. A total of 12 valves from 10 patients were examined. These included 8 native mitral valves and 2 native aortic valves, 1 prosthetic mitral valve, and 1 aortic homograft valve. All tissue valves were irregularly thickened, with varying degrees of distortion of the collagen layers. Chronic inflammatory infiltrates were observed in all tissue valves to a variable extent. Neovascularization was observed in 9 cases. Calcification (observed in 5 cases) varied from none to extensive. Among the native valves, 6 displayed small $(<0.5 \mathrm{~cm}$ in diameter), granular fibrinous vegetations. These ranged from being flat and visible only microscopically to raised and rounded or verrucous deposits. In 1 case the vegetations completely encircled mitral annulus at the line of closure. The prosthetic mitral valve and aortic homografts had similar small vegetations. Microscopically, the observed vegetations in all cases consisted of fibrin thrombi with minimal inflammatory infiltrate (see Figure 1). All Brown and Brenn stains for microorganisms were negative.

\section{Early Outcome}

Mortality. One intraoperative death occurred due to intractable right ventricular failure after MVR. Another patient (patient 4) who had an uncomplicated immediate postoperative course developed staphylococcal sepsis due to 
TABLE 2. Clinical data

\begin{tabular}{|c|c|c|c|c|c|c|c|c|c|}
\hline Case & $\begin{array}{c}\text { Disease } \\
\text { duration } \\
\text { (y) }\end{array}$ & $\begin{array}{l}\text { History of } \\
\text { abortion }\end{array}$ & $\begin{array}{c}\text { History of } \\
\text { thromboembolism }\end{array}$ & CNS & Thrombocytopenia & Anemia & CRF & SLE & Medications \\
\hline 1 & 14 & No & Yes & Yes & Yes & Yes & Yes & Yes & $\mathrm{P}, \mathrm{Cy}, \mathrm{C}$ \\
\hline 2 & 8 & Yes & No & Yes & Yes & Yes & No & No & $P, C$ \\
\hline 3 & 10 & No & Yes & Yes & Yes & Yes & Yes & No & $P, C, A$ \\
\hline 4 & 10 & Yes & Yes & Yes & Yes & Yes & Yes & Yes & $\mathrm{P}, \mathrm{C}$ \\
\hline 5 & 1 & No & Yes & No & Yes & Yes & Yes & No & $P, C, A$ \\
\hline 6 & 15 & Yes & No & Yes & No & Yes & No & Yes & $\mathrm{P}, \mathrm{Cy}, \mathrm{A}$ \\
\hline 7 & 9 & No & Yes & Yes & Yes & No & No & Yes & $\mathrm{P}, \mathrm{Cy}$ \\
\hline 8 & 1 & Male & Yes & Yes & Yes & Yes & No & No & No \\
\hline 9 & 7 & Male & Yes & Yes & Yes & No & Yes & No & C, A \\
\hline 10 & 22 & No & Yes & Yes & No & No & No & Yes & C \\
\hline
\end{tabular}

$A$, Aspirin; $C$, Coumadin; $C N S$, central nervous system involvement; $C R F$, chronic renal failure, creatinine $>130 \mathrm{mEq} / \mathrm{dL} ; C y$, cyclophosphamide.

TABLE 3. Operative data and outcome

\begin{tabular}{|c|c|c|c|c|c|c|c|c|}
\hline Case & Procedure & Incision & $\begin{array}{l}\text { Bypass/cross } \\
\text { clamp time }\end{array}$ & $\begin{array}{c}\text { Minimal } \\
\text { temperature } \\
\left({ }^{\circ} \mathrm{C}\right)\end{array}$ & $\begin{array}{l}\text { Cardiotonic } \\
\text { support }\end{array}$ & $\begin{array}{l}\text { Operative } \\
\text { outcome }\end{array}$ & $\begin{array}{l}\text { Late outcome } \\
\text { (mo) }\end{array}$ & $\begin{array}{l}\text { Follow-up } \\
\text { (mo) }\end{array}$ \\
\hline 1 & MVR (CM), TA & Sternotomy & $243 / 126$ & 24 & + & Death, day 1 & & \\
\hline 2 & MVR (CM) & Sternotomy & $94 / 52$ & 25 & + & & $\begin{array}{l}\text { Re-MVR } \\
\text { Death }\end{array}$ & $\begin{array}{l}90 \\
96\end{array}$ \\
\hline 3 & MVR (HC) & Sternotomy & $130 / 80$ & 28 & + & & Death & 13 \\
\hline 4 & MVR (SJM), TA & Sternotomy & $127 / 61$ & 27 & + & Death, day 22 & & \\
\hline 5 & MVR (CM), AVR (CM) & Sternotomy & $123 / 85$ & 28 & - & & $\begin{array}{l}\text { Splenic embolus (3) } \\
\text { stroke (10) }\end{array}$ & 42 \\
\hline 6 & MVR (CM) & Thoracotomy & $67 / 46$ & 34 & - & & & 32 \\
\hline 7 & MVR (CM) & Sternotomy & $107 / 70$ & 30 & - & & & 33 \\
\hline 8 & AVR (homograft) & Sternotomy & $140 / 102$ & 30 & - & ARDS, day 1 & Re-AVR (15) & 52 \\
\hline 9 & AVR (CM) & Sternotomy & $110 / 84$ & 30 & - & & & 7 \\
\hline 10 & MVR (SJM) & Sternotomy & $71 / 41$ & 31 & - & TIA, day 21 & & 6 \\
\hline
\end{tabular}

$A R D S$, Adult respiratory distress syndrome; $A V R$, aortic valve replacement; $C M$, CarboMedics; $H C$, Hancock; $M V R$, mitral valve replacement; $S J M$, St Jude Medical; $T A$, tricuspid annuloplasty; $T I A$, transient ischemic attack.

mediastinal wound infection 2 weeks after surgery. Sepsis was complicated by disseminated intravascular coagulation (DIC), resulting in cardiac tamponade and acute hemodynamic collapse. Pericardial drainage was performed; however, the patient died due to septic shock with multiorgan failure.

Early complications. In 1 case (patient 8) surgery was complicated by acute respiratory distress syndrome after pulmonary hemorrhage on the second postoperative day. This patient recovered gradually without mechanical ventilation. Patient 10 suffered from transient dysarthria and left hemiparesis 3 weeks after the operation. She had an INR of 3 upon admission.

\section{Late Outcome}

Mortality. Patient 2 underwent emergency reoperation due to stuck mitral prosthesis after 7.5 years of clinical stability. A pseudoaneurysm then developed at the level of mitral annulus and the patient died as a result of a technical complication related to reoperation.

The postoperative course of patient 3 was uneventful apart from persistent pulmonary hypertension. One year later her hemolytic anemia worsened. Renal failure necessitating hemodialysis developed, and the patient died of pulmonary insufficiency with rapid progression to multiorgan failure.

Complications. Patient 8 underwent reoperation 15 months after his first operation because of partial detachment of the aortic homograft and fresh tear in the left leaflet with severe valvular and paravalvular leak. There was no evidence of infective etiology, and this time the postoperative course was uneventful.

Patient 5 had an uncomplicated operation. Three months after operation she was hospitalized with splenic infarction 


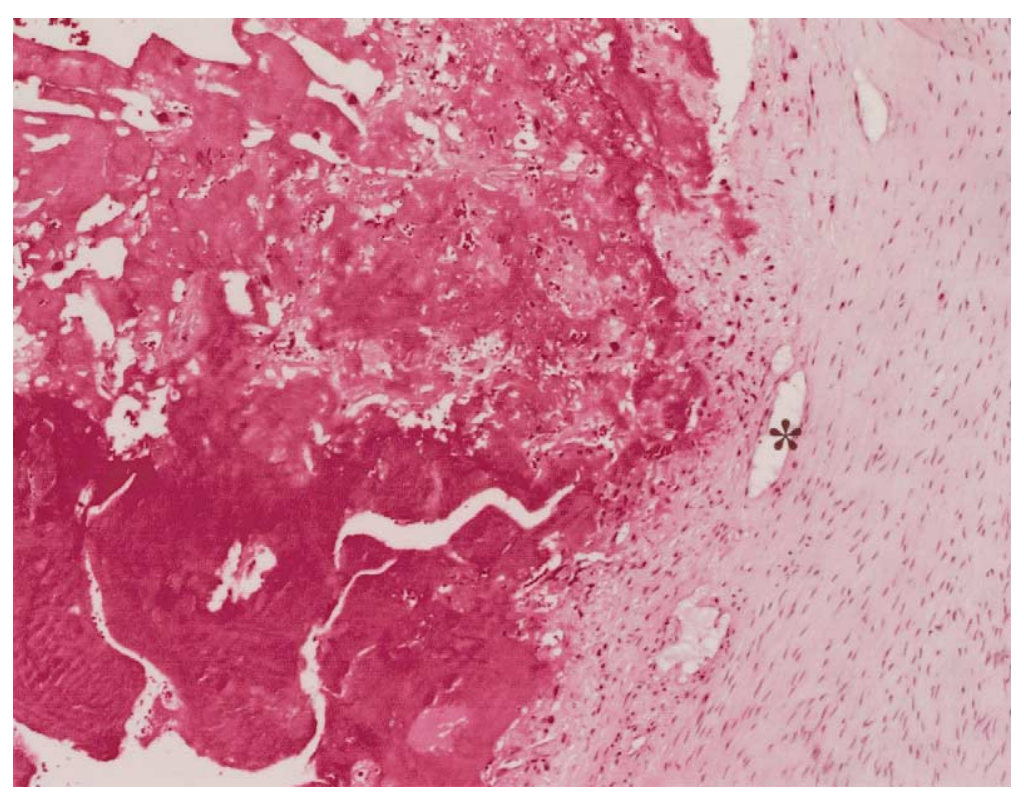

Figure 1. Section of a mitral valve from a patient with systemic lupus erythematosus and secondary antiphospholipid antibody syndrome. The valve is somewhat thickened but not fibrotic in this case. Shown in the left half of the field is a fibrinous vegetation loosely attached to the valve surface, beneath which are small, irregular vascular spaces (neovascularization, asterisk). Inflammation is scant. (Hematoxylin \& eosin, original magnification $\times 50$.)

and 10 months postoperatively she had a large stroke. Her INR was below the recommended therapeutic range during both thromboembolic episodes.

Moderate pulmonary hypertension persisted in 2 patients with preoperative severe hypertension (patients 3 and 4). The 6 long-term survivors have no symptoms of congestive heart failure (NYHA class I). Prosthetic valve function is normal and all have normal or only mildly elevated systolic pulmonary artery pressure.

Altogether, there were 4 deaths among these 10 patients with APLS undergoing valve replacement, of which 2 were late. Early complications, including mortality, occurred in 4 cases. Two patients had late thromboembolic complications. There were no serious late bleeding complications during 281 patient-months of follow-up in the surviving patients. Late structural deterioration occurred in 1 (homograft) of 2 biological valves implanted. The late outcomes were uneventful in only 4 patients. During a follow-up period of up to 8 years, 4 of 8 surviving patients suffered major complications.

\section{Discussion}

Several cardiac manifestations have been reported in patients with APLS, including valvulopathy, intracardiac thrombosis, coronary artery disease, and cardiomyopathy. ${ }^{22-24}$ Various valvular lesions have been demonstrated by echocardiography in $35 \%$ to $82 \%$ of patients. ${ }^{4,23}$ Irregular thickening of the mitral valve, followed by the aortic valve, is the most common finding. Mitral regurgitation is the predominant hemodynamic dysfunction, followed by aortic regurgitation. In many cases more than 1 valve is involved. ${ }^{5,22}$

The pathogenesis of valvulopathy is not entirely clear but it is related to ACL antibodies. A correlation between ACL titer and valvular lesion was found. ${ }^{4}$ Immunoglobulin (including ACL antibodies) and complement deposits have been demonstrated in the subendothelial layer of the affected valve, implying that immune complexes may be involved in the pathogenesis. ${ }^{7}$ Current data suggest an important role for endothelial activation. It has been suggested that the hypercoagulable state may cause deposition of fibrin and platelets on the valves. ${ }^{25}$ These mechanisms could lead to inflammation with subsequent fibrosis, thrombosis, and calcification of the valvular tissue. The significance of the presence of ACL antibodies in patients with valvular heart disease not fulfilling the criteria of APLS is not clear yet, although recent evidence suggests an increased risk of thromboembolic events in such patients. ${ }^{26}$ Only rarely (about $4 \%$ to $6 \%$ ) do patients with APLS develop severe valvular disease that requires surgical treatment. $^{5}$ 
TABLE 4. Literature summary

\begin{tabular}{|c|c|c|c|}
\hline First author & Procedure & $\begin{array}{c}\text { Mortality/ } \\
\text { operated }\end{array}$ & Follow-up \\
\hline Turiel $^{4}$ & MVR & $1 / 1$ & Operative death \\
\hline Alvarez-Blanco ${ }^{6}$ & MVR & $0 / 1$ & Not available \\
\hline Amital $^{7}$ & MVR & $0 / 1$ & Not available \\
\hline Araki $^{8}$ & MVR & $1 / 1$ & Death at 1 year \\
\hline Hasegawa $^{9}$ & MVR & $0 / 1$ & Not available \\
\hline Hogan $^{10}$ & AVR & $0 / 1$ & $\begin{array}{l}\text { Uneventful, } 1.4 \\
\text { year }\end{array}$ \\
\hline Galve $^{11}$ & MVR & $1 / 1$ & Operative death \\
\hline Kato $^{12}$ & MVR & $0 / 1$ & $\begin{array}{l}\text { CNS thrombosis, } \\
\text { re-MVR at } 9 \\
\text { years }\end{array}$ \\
\hline Matsuyama $^{13}$ & AVR & $0 / 1$ & Not available \\
\hline Myers $^{14}$ & $\mathrm{AVR}+\mathrm{MVR}$ & $0 / 1$ & Not available \\
\hline Nojii ${ }^{15}$ & MVR & $0 / 1$ & Uneventful, 4 years \\
\hline Sakagushi ${ }^{16}$ & AVR & $0 / 1$ & Uneventful, 1 year \\
\hline Schumacher ${ }^{17}$ & MVR & $0 / 1$ & Re-MVR 0.75 year \\
\hline Erkan $^{18}$ & MVR, MVR+AVR & $0 / 2$ & Not available \\
\hline East $^{19}$ & MVR & $0 / 2$ & Not available \\
\hline
\end{tabular}

In our retrospective study we observed high morbidity and mortality in patients with APLS who underwent valve replacement. The operative mortality following isolated MVR averaged 6.04\% in 16,105 operated patients from the Society of Thoracic Surgeons (STS) National Cardiac Surgery Database who underwent this procedure; operative mortality was significantly increased by various associated conditions. ${ }^{27}$ Little is known about heart valve replacement in patients with APLS, as data regarding this intervention are limited to several case reports only. A summary of reported cases (Table 4) shows 3 deaths among 17 operated patients with APLS, 2 of them during the perioperative period, similar to our observation. In most of these cases, the follow-up was not reported. ${ }^{6-19}$

The high mortality and the increased morbidity observed in our experience may be accounted for by several factors. These include comorbid states and the consequences of treatment of these conditions and the advanced nature of the valvular heart disease at the time of surgical intervention.

In half of our patients, APLS was secondary to SLE. Results of valve replacement in patients with SLE were described in several case reports and small series only. In a review that summarizes case reports of 12 patients with SLE (with unknown ACL status) who had a total of 14 valves replaced, operative mortality was $25 \%{ }^{28}$

Most of our patients received steroids or other immunosuppressive drugs. Such treatment doubled the operative mortality after either AVR or MVR among 49,073 patients in the STS database. ${ }^{27}$

Mild renal failure, which did not require dialysis, prevailed in 5 of our patients. Renal involvement occurs in as many as $25 \%$ of patients with the primary APLS. ${ }^{29}$ Renal failure is known to be associated with both increased early mortality and late complications in valve replacement. ${ }^{27,30}$

Coexisting thrombophilia and significant thrombocytopenia may also complicate the operative management of patients with APLS. ${ }^{18,19}$ Perioperative thrombosis may be due to antiphospholipid antibodies, warfarin withdrawal before the operation, and catastrophic exacerbation of APLS. ${ }^{31,32}$ Cardiopulmonary bypass with its inherent coagulopathy may augment the bleeding tendency in such patients. Pulmonary apoplexy occurred in 1 of our patients in the early postoperative period. If bleeding diathesis is not observed in the immediate postoperative period, it should be realized that the patients are at increased risk of thromboembolism with significant CNS complications. Therefore, early institution of antiplatelet therapy, in addition to anticoagulant treatment, should be strongly considered.

All but 1 of our patients had either CNS involvement or a history of stroke. Cerebral ischemia is the most common arterial thrombotic manifestation of APLS and is known to be an important cause of morbidity and mortality in this condition. ${ }^{33}$ This is also another risk factor for cardiac surgery, carrying an odds ratio of 1.23 in the STS database. $^{27}$

The treating physician should be aware of the multiple comorbidities in these patients, which will obviously increase the complexity of the medical and surgical care. This in itself should not preclude these patients from surgery. It would be prudent, however, to apply a multidisciplinary approach in the management of such patients.

With regard to the preoperative cardiopulmonary status of our patients, it is noteworthy that severe pulmonary hypertension was observed in 6 cases. Pulmonary hypertension as a part of APLS is due to pulmonary vasculopathy and pulmonary thromboembolism even in the absence of mitral disease. ${ }^{1}$ Despite new medical regimens for pulmonary hypertension, mortality remains high after surgical procedures in such cases. ${ }^{33}$ This condition is also associated with increased mortality and could adversely affect the course after cardiac surgery. ${ }^{27}$ Of note, pulmonary pressure in our long-term survivors has returned to normal or nearnormal values.

Progressive heart failure (NYHA class IV), present in 5 of our patients, is also known to increase the operative risk by $1.36 .^{27}$

As the patients should be treated with anticoagulation due to their hypercoagulopathy, we elected to use a mechanical prosthesis in most cases. Only 2 patients received biological valves because of their own preference. As the valvular involvement in this disease is immunologically mediated, the question arises whether a homograft valve implanted in such patients may be subjected to rapid immunological destruction. We do not have evidence as yet for such. Replacement with a mechanical valve may also min- 
imize the need for repeat, high-risk operations. As discussed earlier, the impaired immunity incurred by the disease and the immunosuppressive treatment may complicate the postoperative course. We observed 1 major infective complication, mediastinitis evolving to generalized sepsis with DIC and multiorgan failure.

With recently improved survival of patients with APLS and SLE due to better medical treatment including prevention of thrombosis and other complications, more patients can be expected to survive long enough to develop progressive valvular disease. As there is neither effective medical treatment available to prevent the development of heart valve disease nor to slow its progression, it is likely that more patients will require valve replacement. Intraoperative valve inspection revealed virulent tissue destruction with significant thickening and verrucous vegetations in many cases, confirmed by the pathological examination. Therefore valve repair is not feasible or inappropriate, rendering replacement as the only option. In this regard, considering the younger age of these patients at the time of surgical intervention and the better prognosis with intensive medical treatment, a mechanical valve substitute may be advantageous over a bioprosthesis.

\section{Conclusion}

Although our series is small and retrospective, it shows that valve replacement in patients with APLS is associated with significant morbidity and mortality as also suggested by review of previously reported cases. This group of patients is characterized by advanced valvular disease with significant pulmonary hypertension and progressive heart failure. Most patients are immune compromised, with renal dysfunction and previous CNS complications. Thus, to reduce the operative risks, such patients should be closely observed and considered for earlier operative intervention. Mechanical substitutes are probably the better choice for these patients, who are usually treated with anticoagulants for other indications. Such policy may minimize the need for further operative interventions carrying higher morbidity and mortality. Prospective studies should clarify the proper timing of operation and the optimal perioperative management.

\section{References}

1. Levine JS, Branch DW, Rauch J. The antiphospholipid syndrome. N Engl J Med. 2002;346:752-63.

2. Asherson RA, Khamashta MA, Ordi-Ros J, et al. The "primary" antiphospholipid syndrome: major clinical and serological features. Medicine (Baltimore). 1989;68:366-74.

3. Espinola-Zavaleta N, Vargas-Barron J, Colmenares-Galvis T, et al. Echocardiographic evaluation of patients with primary antiphospholipid syndrome. Am Heart J. 1999;137:973-8.

4. Turiel M, Muzzupappa S, Gottardi B, Crema C, Sarzi-Puttini P, Rossi E. Evaluation of cardiac abnormalities and embolic sources in primary antiphospholipid syndrome by transesophageal echocardiography. $\mathrm{Lu}$ pus. 2000;9:406-12.
5. Nesher G, Ilany J, Rosenmann D, Abraham AS. Valvular dysfunction in antiphospholipid syndrome: prevalence, clinical features, and treatment. Semin Arthritis Rheum. 1997;27:27-35.

6. Alvarez-Blanco A, Egurbide-Arberas MV, Aguirre-Errasti C. Severe valvular heart disease in a patient with primary antiphospholipid syndrome. Lupus. 1994;3:433-4.

7. Amital H, Langevitz P, Levy Y, et al. Valvular deposition of antiphospholipid antibodies in the antiphospholipid syndrome: a clue to the origin of the disease. Clin Exp Rheumatol. 1999;17:99-102.

8. Araki Y, Tajima K, Shimomura T, et al. A case report on mitral valve replacement associated with antiphospholipid syndrome in systemic lupus erythematosus. Kyobu Geka. 1997;50:480-2.

9. Hasegawa R, Kitahara H, Watanabe K, Kuroda H, Amano J. Mitral stenosis and regurgitation with systemic lupus erythematosus and antiphospholipid antibody syndrome. Jpn J Thorac Cardiovasc Surg. 2001;49:711-3.

10. Hogan WJ, McBane RD, Santrach PJ, et al. Antiphospholipid syndrome and perioperative hemostatic management of cardiac valvular surgery. Mayo Clin Proc. 2000;75:971-6.

11. Galve E, Ordi J, Barquinero J, Evangelista A, Vilardell M, Soler-Soler J. Valvular heart disease in the primary antiphospholipid syndrome. Ann Intern Med. 1992;116:293-8.

12. Kato Y, Isobe F, Sasaki Y, Kodera K, Kumano H, Nagamachi K. Mitral insufficiency associated with primary antiphospholipid syndrome and chronic renal failure. Jpn J Thorac Cardiovasc Surg. 2001;49:171-4.

13. Matsuyama K, Ueda Y, Ogino H, et al. Aortic valve replacement for aortic regurgitation in a patient with primary antiphospholipid syndrome. Jpn Circ J. 1999;63:725-6.

14. Myers GJ, Hirsch GM. Double valve replacement in a patient with anticardiolipin antibody syndrome. Perfusion. 1999;14:397-401.

15. Noji S, Kitamura N, Miki T, Kimura S, Shunto K, Yamaguchi A. Successful surgical treatment of mitral regurgitation associated with anti-phospholipid syndrome and systemic lupus erythematosus. Nippon Kyobu Geka Gakkai Zasshi. 1995;43:1176-81.

16. Sakaguchi G, Minami K, Nakayama S, Tsuneyoshi H. Aortic valve replacement after previous coronary artery bypass grafting in a patient with antiphospholipid syndrome. Jpn J Thorac Cardiovasc Surg. 1998;46:257-9.

17. Schumacher M, Eber B, Dusleag J, et al. Thrombosis of a prosthetic mitral valve in the anticardiolipin syndrome. Dtsch Med Wochenschr. 1995; 120:795-8.

18. Erkan D, Leibowitz E, Berman J, Lokshin M. Perioperative medical management of antiphospholipid syndrome: hospital for special surgery experience, review of literature, and recommendations. J Rheumatol. 2002;29:843-9.

19. East CJ, Clements F, Mathew J, Slaughter TF. Antiphospholipid syndrome and cardiac surgery: management of coagulation in two patients. Anesth Analg. 2000;90:1098-101.

20. Wilson WA, Gharavi AE, Koike T, et al. International consensus statement on preliminary classification criteria for definite antiphospholipid syndrome: report of an international workshop. Arthritis Rheum. 1999;42:1309-11.

21. Edmunds LH, Clark RE, Cohn LH, Grunkemeier GL, Miller DC, Weisel RD. Guidelines for reporting morbidity and mortality after cardiac valvular operations. Ann Thorac Surg. 1996;62:932-5.

22. Cervera R. Recent advances in antiphospholipid antibody-related valvulopathies. J Autoimmun. 2000;15:123-5.

23. Kaplan SD, Chartash EK, Pizzarello RA, Furie RA. Cardiac manifestations of the antiphospholipid syndrome. Am Heart J. 1992;124: 1331-8.

24. Hojnik M, George J, Ziporen L, Shoenfeld Y. Heart valve Involvement (Libman-Sacks endocarditis) in the antiphospholipid syndrome. Circulation. 1996;93:1579-87.

25. Afek A, Shoenfeld Y, Manor R, et al. Increased endothelial cell expression of alpha3beta1 integrin in cardiac valvulopathy in the primary (Hughes) and secondary antiphospholipid syndrome. Lupus. 1999;8:502-7.

26. Bulckaen HG, Puisieux FL, Bulckaen ED, et al. Antiphospholipid antibodies and the risk of thromboembolic events in valvular heart disease. Mayo Clin Proc. 2003;78:294-8. 
27. Edwards FH, Peterson ED, Coombs LP, et al. Prediction of operative mortality after valve replacement surgery. J Am Coll Cardiol. 2001; 37:885-92.

28. Dajee H, Hurley EJ, Szarnicki RJ. Cardiac valve replacement in systemic lupus erythematosus. J Thorac Cardiovasc Surg. 1983;85:718-26.

29. Daugas E, Nochy D, Huong DL, et al. Antiphospholipid syndrome nephropathy in systemic lupus erythematosus. J Am Soc Nephrol. 2002;13:42-52.

30. Anderson RJ, O'Brien M, MaWhinney S, et al. Mild renal failure is associated with adverse outcome after cardiac valve surgery. Am J Kidney Dis. 2000;35:1127-34.

31. Bick RL, Arun B, Frenkel EP. Antiphospholipid-thrombosis syndromes. Haemostasis. 1999;29:100-10.

32. Yamamoto $\mathrm{T}$, Ito $\mathrm{M}$, Nagata $\mathrm{S}$, et al. Catastrophic exacerbation of antiphospholipid syndrome after lung adenocarcinoma biopsy. J Rheumatol. 2000;27:2035-7.

33. Amigo MC. Prognosis in antiphospholipid syndrome. Rheum Dis Clin North Am. 2001;27:661-9. 